\title{
ENSINO DE QUÍMICA EM UM CURSO TÉCNICO EM ELETROTÉCNICA: PERCEPÇÕES E REFLEXÕES SOBRE A INTEGRAÇÃO
}

\author{
Chemistry Teaching in an Electrotechnics Technical Course: \\ perceptions and reflections on integration
}

\author{
Luciane Magda Melo Araújo ${ }^{1}$ \\ Patrícia Fernandes Lootens Machado ${ }^{2}$ \\ Mírian Rejane Magalhães Mendes ${ }^{3}$
}

\begin{abstract}
Resumo: Professores que atuam no Ensino Médio Integrado à Educação Profissional (EMI) revelam dificuldades para desenvolver propostas didáticas que apresentem a ideia de trabalho como princípio educativo, o que se constitui como fundamento da educação politécnica. Diante disso, o objetivo dessa pesquisa foi analisar o desenvolvimento de uma proposta didática que visava à integração entre a Química e disciplinas específicas do curso Técnico em Eletrotécnica (TE), ofertado de forma Integrada em uma escola pública federal. Os dados foram obtidos da análise do Projeto Político Pedagógico do Curso, de entrevistas com docentes, de filmagens das aulas de Química, da avaliação das atividades didáticas dos alunos e dos registros da professora. A análise dos dados teve caráter predominantemente qualitativo e os resultados demonstram que a proposta contribuiu para o entendimento do que é o EMI pelos alunos; a sensibilização deles em relação a aspectos sociais e ambientais associados ao exercício da profissão; e a integração de conhecimentos químicos e de outras Ciências aos conhecimentos específicos da profissão de TE. Isso reforçou a necessidade de se ampliar e aprofundar estudos sobre a efetivação da integração nos cursos técnicos de nível médio, no intuito de se superar concepções e práticas simplistas, nas quais a integração se resume a somar ou subordinar conteúdos de diferentes disciplinas.
\end{abstract}

Palavras-chave: Educação Profissional Técnica de Nível Médio. Ensino Médio Integrado. Politecnia.

Abstract: Teachers who work in High School Integrated to Professional Education (EMI) programs express difficulties in developing didactic proposals that present the idea of work as

\footnotetext{
1 Mestre em Ensino de Ciências pela Universidade de Brasília e Licenciada em Química pelo Centro Universitário de Formiga, (UNIFOR-MG). Professora EBTT do Instituto Federal de Educação, Ciência e Tecnologia do Triângulo Mineiro-Campus Patos de Minas (IFTM). ORCID: 0000-0003-1459-2396. E-mail: luciane@iftm.edu.br.

2 Doutora e Mestre em Engenharia com Área de Concentração Ciência dos Materiais, pela Universidade Federal do Rio Grande do Sul (UFRGS) e Bacharel em Química, pela Universidade Federal do Ceará (UFC). Professora Associada do Instituto de Química da Universidade de Brasília e orientadora do Programa de Pós-Graduação em Educação em Ciências da UnB (PPGEduC). ORCID: 0000-0003-0219-1472. E-mail: plootens@unb.br.

3 Doutora em Educação e Mestre em Ensino de Ciências, ambos pela Universidade de Brasília (UnB) e Bacharel em Farmácia e Bioquímica pela Universidade de Ouro Preto (UFOP). Professora Titular (EBTT) no Instituto Federal do Norte de Minas Gerais-IFNMG. ORCID: 0000-0002-5429-9103. E-mail: mirianrmm@ gmail.com.
} 
an educational principle, which is the foundation of polytechnic schools. The objective of this research was to analyze the development of a didactic proposal for the integration of the Chemistry class and other specific classes in the Electrotechnics Technical Course of a public school. The data was obtained from: the analysis of the course's Pedagogical Project, interviews with teachers, Chemistry classes recordings, the analysis of didactic activities carried out by the students and the teacher's records. Data analysis was predominantly qualitative and the results show that the proposal contributed to: the students' understanding of what the EMI is, the students' awareness of social and environmental issues associated with the profession; and the integration of Chemistry and other sciences to the specific studies of the Electrotechnology Technician profession. These results reinforce the need to broaden and deepen the study of integration in high school technical courses, in order to overcome simplistic conceptions and practices in which integration consists in adding content from different disciplines.

Keywords: Professional Technical Education. Integrated High School. Polytechnic.

\section{Introdução}

O desafio de atuar como professor no Ensino Médio Integrado à Educação Profissional $(\mathrm{EMI})^{4}$ tem gerado questionamentos sobre essa modalidade de ensino. Muitos profissionais sentem dificuldades em planejar aulas que articulem, de forma dialógica, conhecimentos da base geral com conhecimentos da base específica. Tal articulação, considerando a perspectiva politécnica (KUENZER, 2009; RAMOS, 2007; SAVIANI, 1989; VIGOTSKI, 2003), é o propósito dessa modalidade de ensino. Segundo Kuenzer (1999), isso ocorre porque a grande maioria dos cursos de licenciatura não vem preparando os licenciandos para atuarem no EMI.

Para Machado (2009), o ensino envolvendo currículos integrados deve experimentar hipóteses de trabalho e propostas de ação didática que orientem uma abordagem relacional de conteúdos diferentes, considerando que esta diferenciação não pode ser tomada como absoluta. Assim, educadores e estudantes atuantes no ensino integrado precisam romper com a fragmentação dos conteúdos e buscar pela inter-relação de um conjunto de conhecimentos que gerem aprendizagens significativas.

A oferta do EMI deve levar em consideração características e necessidades sociais, econômicas e culturais da população a ser atendida, tendo como eixos estruturantes a ciência, a tecnologia, a cultura e o trabalho (MACHADO, 2009; MOURA, 2010; RAMOS, 2007). Na realidade, o que se observa é que o Ensino Médio convencional ${ }^{5}$, na prática, distancia-se dessa ideia, uma vez que tem sua ação educativa centrada no caráter propedêutico, dissociada das discussões relativas ao mundo do trabalho e à profissionalização (MOURA, 2012).

De acordo com o Documento Base da Educação Profissional Técnica de Nível Médio Integrada ao Ensino Médio (BRASIL, 2007), a prática pedagógica deve romper com o conhecimento fragmentado e descontextualizado presente em várias escolas nos dias atuais. Uma possível solução seria trabalhar na perspectiva de educação politécnica, que segundo Ramos (2012), busca superar a dicotomia entre trabalho manual e trabalho intelectual, cultura

\footnotetext{
${ }^{4}$ Neste trabalho, será utilizada a expressão Ensino Médio Integrado (EMI) de uso corrente na legislação e no meio acadêmico e que se refere à integração do Ensino Médio à Educação Profissional. No entanto, as autoras consideram que a Educação Profissional é que se integra ao Ensino Médio, visto ser esta a etapa de formação básica do cidadão.

${ }^{5} \mathrm{O}$ termo convencional para caracterizar o Ensino Médio não profissionalizante será adotado neste trabalho.
} 
geral e cultura técnica. Assim, contribui para o domínio dos fundamentos científicos associados às diferentes técnicas que caracterizam o processo de trabalho.

Esse mesmo documento aponta a dificuldade de se implementar a politecnia de forma universal e unitária e propõe como solução transitória e viável um ensino médio que integre os conhecimentos científicos sócio historicamente consolidados aos objetivos de formação profissional (BRASIL, 2007). Diante disso, surge a seguinte questão de pesquisa: como promover a integração, em perspectiva politécnica, entre a Química e disciplinas específicas no curso Técnico em Eletrotécnica ofertado de forma Integrada?

Neste trabalho, foi abordada, prioritariamente, a dimensão epistemológica e pedagógica da integração de conhecimentos da formação geral e específica, na busca por superar concepções que associam a integração a somar, superpor ou subordinar esses conhecimentos uns aos outros (RAMOS, 2007).

\section{$2 \mathrm{O}$ ensino médio integrado à educação profissional: concepções e princípios}

A proposta de integração entre a educação profissional técnica de nível médio e o Ensino Médio é regulamentada pelo Decreto n. 5.154/04 que revogou e substituiu o Decreto n. 2.208/97 e regulamentou o $\S 2^{\circ}$ do Artigo 36 e os Artigos 39 a 41 da Lei $n^{\circ}$ 9.394/96. Ao contrário do que previa e fomentava o Decreto de 1997, o atual recoloca a possibilidade da oferta de Educação Profissional Técnica de Nível Médio e do Ensino Médio de forma integrada, em um mesmo curso, com currículo próprio e articulado organicamente (GRABOWSKI, 2006).

A formação humana que integra estudo e trabalho e abarca aspectos físico, mental, intelectual, cultural, estético, político e prático laboral é chamada de omnilateral. Segundo Ciavatta (2012), esse modelo de formação defende uma perspectiva de compreensão teórica e prática dos fundamentos científicos das múltiplas técnicas utilizadas no processo produtivo e já era almejado por utopistas do Renascimento, como Comenius, e por socialistas como SaintSimon, Robert Owen e Fourier, que defendiam a formação completa para os trabalhadores.

Ciavatta aponta ainda que a formação integrada implica reflexões sobre a divisão social, que se manifesta no sistema educacional, suscitando questionamentos tais como: A quem destinar a educação? Educar a todos ou diferenciar tipos de educação para uns e outros? Nesse sentido, Ramos (2007, p. 2) defende que

[...] a realidade nos impõe sempre a pensar sobre o tipo de sociedade que visamos quando educamos. Visamos a uma sociedade que exclui, que discrimina, que fragmenta os sujeitos e que nega direitos; ou visamos a uma sociedade que inclui, que reconhece a diversidade, que valoriza os sujeitos e sua capacidade de produção da vida, assegurando direitos sociais plenos? Nós nos colocamos, na segunda posição que, em síntese, persegue a construção de uma sociedade justa e integradora.

Este posicionamento nos remete ao conceito de Ensino Médio Integrado (EMI), de natureza filosófica, que expressa uma concepção de formação humana com base na integração de todas as dimensões da vida no processo educativo, visando à formação omnilateral dos indivíduos, que busca integrar trabalho, cultura e ciência, em oposição à formação unilateral, baseada na abordagem dissociada dessas dimensões (RAMOS, 2007).

Tendo em vista a perspectiva de uma formação omnilateral, o EMI pode permitir uma formação politécnica em que ciência, cultura e trabalho estão incorporados e integrados, sendo que a ciência corresponde a conhecimentos sistematicamente produzidos e validados pela humanidade; a cultura aos valores éticos e estéticos que orientam as normas de conduta de uma sociedade e o trabalho compreendido como realização inerente ao ser humano e, 
paralelamente, como prática econômica (RAMOS, 2007). Todos estes elementos permeiam as dimensões teórico-metodológicas da Educação Profissional, que assumem o trabalho como princípio educativo (NASCIMENTO; AMORIM, 2008), o que

[...] implica referir-se a uma formação baseada no processo histórico e ontológico de produção da existência humana, em que a produção do conhecimento científico é uma dimensão. Por exemplo, a eletricidade como força natural abstrata existia mesmo antes de sua apropriação como força produtiva, mas não operava na história. Enquanto era uma hipótese para a ciência natural era um "nada" histórico até que passa a se constituir como conhecimento que impulsiona a produção da existência humana sobre as bases materiais e sociais concretas. (RAMOS, 2012, p.120).

Assim, a implantação e a ampliação do EMI implicam em uma proposta de superação para a educação brasileira, em que os conhecimentos das ciências exatas, sociais e humanas serão contemplados de igual forma, em nível de importância e de conteúdo, visando a uma formação integral do cidadão autônomo e emancipado. A formação integral não se preocupa apenas com a competência técnica, mas também, com o compromisso ético de formação de cidadãos que atuem para a edificação de uma sociedade justa e igualitária (MOURA, 2010).

Ressalta-se que o valor psicológico e pedagógico da politecnia nos leva a reconhecê-la como diretriz fundamental da educação pelo trabalho. Considerando as premissas psicológicas da politecnia, assume-se que, em todo processo de trabalho, o homem vivencia um duplo papel, visto que ele é, tanto a fonte direta de energia física, como o organizador, dirigente desse processo. No primeiro aspecto, pode ser substituído, no segundo, não (VIGOTSKI, 2003). É o que vem ocorrendo devido ao avanço tecnológico dos meios de produção, levando à diminuição da exigência do trabalho físico e demandando, cada vez mais, o trabalho mental, de organização. Dessa forma, percebe-se a necessidade da formação politécnica, não no seu sentido literal, como reunião de várias técnicas isoladas e fragmentadas em uma só pessoa (SAVIANI, 1989), mas como o entendimento dos fundamentos gerais do trabalho humano.

Diante do exposto, infere-se que a politecnia, ao introduzir o aluno no sentido da produção, oportuniza a ele relacionar os conhecimentos científicos às questões sociais contemporâneas; significar os procedimentos técnicos a serem desenvolvidos para o exercício de uma profissão e vivenciar relações de dominação e subordinação, excluindo o caráter negativo de ambos, favorecendo a formação e o desenvolvimento do comportamento consciente e da vontade.

Saviani (1989, p. 17), em sintonia com as ideias de Vigotski (2003) sobre politecnia, concebe que ela se refere

[...] ao domínio dos fundamentos científicos das diferentes técnicas que caracterizam o processo de trabalho produtivo moderno. Está relacionada aos fundamentos das diferentes modalidades de trabalho e tem como base determinados princípios, determinados fundamentos, que devem ser garantidos pela formação politécnica.

Ramos (2007, p. 2), no mesmo sentido, aponta que politecnia "significa uma educação que possibilita a compreensão dos princípios científico-tecnológicos e históricos da produção moderna, de modo a orientar os estudantes à realização de múltiplas escolhas". Assim, compreende-se que a noção de politecnia se vincula à concepção do trabalho como princípio educativo geral, assumindo ser ele que define a existência humana, visto que possibilita ao indivíduo se constituir como tal, no processo contínuo de produção da própria existência (KUENZER, 2009; SAVIANI, 2003).

Nesse sentido, a presença da profissionalização no Ensino Médio deve ser compreendida como uma necessidade social e ao mesmo tempo como meio pelo qual a categoria trabalho ganha espaço na formação como princípio educativo. A integração entre a educação profissional técnica de nível médio e o Ensino Médio pressupõe que a educação 
geral se torne parte inseparável da educação profissional em todos os campos em que se dá a preparação para o trabalho (RAMOS, 2012), rompendo com o modelo cultural que hierarquiza os conhecimentos, conferindo menor valor aos de ordem técnica, associados ao trabalho manual (MACHADO, 2009). Assim, conhecimentos gerais e conhecimentos profissionais somente se distinguem metodologicamente e em suas finalidades situadas historicamente. No entanto, epistemologicamente, esses conhecimentos formam uma unidade (RAMOS, 2011). Desta forma, compreende-se que a sobreposição de disciplinas da formação geral e da formação específica no decorrer de um curso não é o mesmo que integração. Assim também, não é tratada como integração a simples adição de um ano de estudos profissionais a três do Ensino Médio. Para que ocorra a integração de fato, é necessário que conhecimentos da base comum e da base específica sejam relacionados continuamente ao longo da formação, sob os eixos da ciência, do trabalho, da cultura e da tecnologia (RAMOS, 2012).

Atualmente, em nosso país, muitas escolas têm como único objetivo aprovar seus alunos nos processos seletivos de acesso às universidades públicas. De forma reducionista, trabalham exclusivamente com o propósito propedêutico, adotando métodos de uma educação que deixam de lado a formação integral. O EMI, em contraposição a essa perspectiva e tendo o trabalho como princípio educativo, engloba em um escopo único e indissociável os objetivos do Ensino Médio e da formação profissional de nível médio, ampliando as possibilidades do aluno, ao prover uma educação para o exercício crítico da cidadania, para a empregabilidade e para o acesso a níveis superiores de formação. Assim sendo, os professores das diversas disciplinas de formação geral devem, em sua atuação, agirem também como professores da formação profissional, desde que se considere o processo de produção das respectivas áreas profissionais na perspectiva da totalidade (BRASIL, 2007). Esta foi a concepção assumida no delineamento e desenvolvimento da proposta didática de intervenção, objeto de análise neste trabalho.

\section{Percurso metodológico}

Trata-se de uma pesquisa do tipo intervenção pedagógica (DAMIANI et al., 2013) conduzida pelo paradigma da pesquisa qualitativa de natureza descritiva, orientada por características básicas apontadas por Bogdan e Biklen (2003), que consideram o ambiente natural como a fonte de dados e o pesquisador como seu principal agente. Segundo estes autores, o interesse da pesquisa qualitativa está centrado mais no processo do que com o produto e o pesquisador, por meio do contato direto e prolongado com o ambiente, busca conhecer os significados apropriados pelos participantes. Nessa perspectiva, o objetivo do trabalho foi analisar uma intervenção desenvolvida durante o segundo trimestre do ano letivo de 2015, com uma turma de 29 alunos do primeiro ano do curso Técnico em Eletrotécnica Integrado ao Ensino Médio em uma escola da rede federal de ensino, localizada na região do Alto Paranaíba do estado de Minas Gerais.

Antes mesmo de iniciar a proposta, buscou-se conhecer qual o entendimento dos estudantes sobre o que seria um curso integrado. O desenvolvimento da proposta ocorreu uma vez por semana, em aulas geminadas com duração de $1 \mathrm{~h} 40 \mathrm{~min}$, compondo um total de 22 aulas, equivalente a, aproximadamente, 18 horas-aulas. Lüdke e André (1986) orientaram a escolha dos instrumentos de coleta de dados, a saber: a entrevista, a observação e a análise documental. A coleta de dados foi realizada por meio das filmagens das aulas lecionadas e das respostas às atividades didáticas realizadas pelos estudantes (tarefas de casa, atividades experimentais investigativas, fichas de avaliação de aprendizagem e avaliações). Esses dados compuseram o corpus de análise juntamente com o relato da professora regente da turma sobre o trabalho, que acompanhou presencialmente a intervenção e os registros da professora 
pesquisadora, elaborados e enriquecidos logo após as aulas e enriquecido com as discussões entre as pesquisadoras. Este último instrumento, por seu caráter analítico reflexivo, foi determinante para resgatar passagens relativas ao processo ensino-aprendizagem, às necessidades surgidas no contexto, às percepções e reflexões decorrentes. Três frentes basicamente organizam a análise: a primeira delas abarcou os momentos iniciais de pensar a integração dos conhecimentos específicos aos conteúdos de química juntamente com professores das disciplinas específicas; a segunda frente relata a elaboração das atividades e do material utilizado na intervenção; a terceira compreendeu a avaliação do processo de intervenção, as percepções decorrentes e as reflexões necessárias.

A Direção da Instituição autorizou a realização da pesquisa, que se iniciou pela análise do Projeto Pedagógico do Curso (PPC), para levantar possibilidades de integração entre os conhecimentos de Química e as disciplinas profissionalizantes. Após a identificação das disciplinas da área técnica, os respectivos professores regentes do curso Técnico em Eletrotécnica foram entrevistados. Os professores tomaram ciência da natureza da investigação e formalizaram o consentimento de sua participação na pesquisa assinando o Termo de Consentimento Livre e Esclarecido. O objeto da investigação foi identificar as técnicas e os materiais utilizados por profissionais de Eletrotécnica e de conteúdos de Química essenciais para a aprendizagem dos conteúdos e técnicas a serem ensinados nas disciplinas específicas selecionadas. As entrevistas, áudio-gravadas, foram consideradas essenciais não somente para a identificação das possibilidades de integração, mas para subsidiar o desenvolvimento das estratégias didáticas, a partir da integração de conteúdos gerais e específicos na perspectiva de uma formação politécnica.

\section{Do processo coletivo de pensar a integração}

Foram adotados dois critérios orientadores para a escolha das disciplinas específicas: o primeiro, terem a Química como conhecimento estruturante delas e, o segundo, os conteúdos estruturantes de Química a serem trabalhados estarem em conformidade com aqueles previstos para o primeiro ano do curso. Daí, surgiram: Fundamentos de Saúde, Segurança no Trabalho e Meio Ambiente; Circuitos Elétricos e Projeto.

Das entrevistas com os professores das disciplinas específicas, foi depreendido que a medição elétrica, o descarte de materiais eletroeletrônicos, e o uso de equipamentos de proteção individual e coletiva eram os temas possíveis para se abordar princípios da ciência importantes para a formação politécnica do aluno. Como Braibante e Pazinato (2014, p. 820), entende-se que a "abordagem de temáticas no ensino de Química visa favorecer o processo de ensino e aprendizagem e contribuir para a formação do caráter cidadão dos alunos". Nesse sentido, para se promover a integração entre a Química e as disciplinas específicas, citadas, definiu-se trabalhar com a temática "Medições elétricas", buscando integrar técnicas, conceitos de ciência, questões ambientais e de segurança no trabalho, a ela relacionados. Entende-se que ao desenvolver essa temática, foram contemplados não somente objetivos relacionados à formação profissional, mas também aqueles relacionados à formação geral preconizada no Decreto 5.154/2004, que orienta a consolidação do Ensino Médio como "formação básica unitária e politécnica, centrada no trabalho, na ciência e na cultura".

Estabelecida a temática, foi definido que a utilização do multímetro e dos equipamentos de proteção individual (EPI) e coletiva (EPC), apontados pelos entrevistados como ferramentas importantes para o trabalho do Técnico em Eletrotécnica, corresponderia à dimensão técnica a ser abordada na proposta. Para sua compreensão, seriam trabalhados os conhecimentos de ciências que se fizessem necessários, sem perder de vista sua adequação ao nível de ensino, primeiro ano do EMI, e o perfil dos alunos. Diante deste entendimento, foi 
estabelecido que, quando o conhecimento escolar fosse de maior complexidade, se trabalharia com definições operacionais ${ }^{6}$. Por se compreender que a formação politécnica implica o desenvolvimento da capacidade de análise das inter-relações Ciência-Tecnologia-Sociedade CTS associadas ao processo produtivo, optou-se por incluir na proposta discussões sobre pilhas e baterias, suas composições e as implicações socioambientais decorrentes do descarte inadequado de materiais eletroeletrônicos.

Ao longo deste trabalho é possível perceber que, na proposta de ensino, a escolha do que ensinar não partiu de informações de uma sequência didática presente em um livro ou de uma hierarquização sistematizada e linear dos conteúdos. Foi desenvolvido para a intervenção uma forma alternativa de planejamento, na qual a definição do que seria ensinado teve como referência as técnicas utilizadas pelo Técnico em Eletrotécnica.

\section{Da preparação do processo de integração}

Ao desenvolver as atividades didáticas em perspectiva politécnica, foram trabalhados conceitos científicos e definições operacionais do cotidiano do Técnico em Eletrotécnica. Conteúdos mais avançados como Eletroquímica e Ligações Químicas, apesar de terem sido citados pelos entrevistados, não foram tratados nesta proposta, por necessitarem de conhecimentos prévios ainda não estudados pelos alunos. Destaca-se que, além de conhecimentos químicos, foram abordados também conceitos de outras ciências, necessários para a compreensão da temática. Desta forma, pôde ser vivenciada, no desenvolvimento da proposta, a efetivação da interdisciplinaridade, dimensão inerente à integração. Essa abordagem de conceitos de outras disciplinas não implicou em que eles não fossem desenvolvidos pelos respectivos professores conforme seus planejamentos e limitou-se ao necessário para possibilitar a compreensão, por parte dos alunos, dos fundamentos científicos associados aos conhecimentos, procedimentos e técnicas que integram a formação do profissional técnico em eletrotécnica.

Diante do exposto, a Proposta Didática fundamentou-se em uma perspectiva investigativa, composta por quatro (4) Unidades, em que foram utilizados diferentes estratégias e recursos didáticos. Dentre elas destaca-se as atividades experimentais investigativas, que permitiram articulações entre o fazer e o pensar. Já dentre os recursos, o destaque foram os vídeos, que possibilitaram abordagens contextualizadas e interdisciplinares, além de terem despertado o interesse e a curiosidade dos alunos. Ao utilizar os vídeos como recurso didático, tendo em vista a consecução dos objetivos propostos da intervenção, foram adotados cuidados, quais sejam: propor, antes ou durante a exibição, questionamentos para guiar o olhar dos alunos e interromper ou reexibir partes do vídeo para destacar pontos importantes. Estes procedimentos são formas de direcionar a atenção do aluno para o que deve ser aprendido e instigar a sua participação, não deixando que ele se disperse ou permaneça passivo na sala de aula (SILVA; MACHADO; TUNES, 2010).

A anuência dos pais e/ou responsáveis dos 29 estudantes foi dada unanimemente por meio do Termo de Consentimento Livre e Esclarecido. $\mathrm{O}$ anonimato dos participantes foi

\footnotetext{
${ }^{6}$ Denomina-se definição operacional o significado concreto de um termo construído a partir dos procedimentos utilizados para produzir, manipular ou medir algo, sem utilizar de significados abstratos que caracterizam um objeto ou um fenômeno estudado. Por exemplo, um professor poderá explicar o que é temperatura, a seu aluno, operacionalmente, através da leitura do número indicado por um termômetro. As definições operacionais podem ser trabalhadas no ensino a partir de atividades em que os alunos compreendam: o para que utilizar, o como utilizar, onde utilizar, como fazer e como medir. (Disponível em: http://www.ime.unicamp.br/ hildete/oper.pdf).
} 
Revista de Educação, Ciência e Tecnologia

acordado nesse Termo e efetivado por meio da codificação de identidade dos participantes, que são identificados aleatoriamente nesse relato por A1, A2, A3... A29.

A metodologia de ensino adotada durante os encontros teve a seguinte organização geral: apresentação do tema do encontro e de uma questão problematizadora, seguida pelo desenvolvimento das atividades planejadas, associando a elas as definições operacionais e os conceitos relacionados a tal questão e, por fim, a avaliação. Trabalhar com as definições operacionais antes de abordar os conceitos foi a opção metodológica adotada, por se considerar que ambos têm espaço no processo ensino-aprendizagem e são relevantes para a formação profissional técnica. No Quadro 1 consta uma síntese do que os estudantes deveriam ser capazes de realizar ao final de cada um dos encontros.

Quadro 1 - Objetivos de ensino ao longo de cada Unidade dos onze encontros.

\begin{tabular}{|c|c|}
\hline \multicolumn{2}{|r|}{ UNIDADE 1 - O CURSO TÉCNICO EM ELETROTÉCNICA } \\
\hline Encontro & Objetivos de Ensino \\
\hline 1 & $\begin{array}{l}\text { 1. Enunciar as atividades profissionais do Técnico em Eletrotécnica; 2. Distinguir } \\
\text { conhecimentos e técnicas relacionados à Eletrotécnica; } 3 \text {. Descrever as áreas de atuação do } \\
\text { Técnico em Eletrotécnica. 4. Reconhecer materiais e técnicas utilizados por esse Técnico. }\end{array}$ \\
\hline \multicolumn{2}{|r|}{ UNIDADE 2 - MEDIÇÕES ELÉTRICAS } \\
\hline Encontro & Objetivos de Ensino \\
\hline 2 & $\begin{array}{l}\text { 1. Reconhecer a medição elétrica como uma das práticas do Técnico em Eletrotécnica; } 2 . \\
\text { Reconhecer o multímetro como ferramenta de trabalho deste Técnico; } 3 \text {. Relatar as três } \\
\text { principais funcionalidades do multímetro (ohmímetro, voltímetro e amperímetro); } 4 \text {. Utilizar o } \\
\text { multímetro para realizar medidas elétricas de voltagem e amperagem. }\end{array}$ \\
\hline 3 & $\begin{array}{l}\text { 1. Realizar testes de voltagem e amperagem em pilhas e em circuitos elétricos; } 2 \text {. Definir } \\
\text { operacionalmente voltagem e amperagem. Identificar associações de pilhas em série e em } \\
\text { paralelo; } 3 \text {. Explicar a diferença dos valores de voltagem para circuitos de pilhas em série e em } \\
\text { paralelo, bem como a diferença dos valores de amperagem; } 4 \text {. Distinguir o brilho da lâmpada } \\
\text { dos circuitos em série e paralelo a partir dos valores de voltagem e amperagem. }\end{array}$ \\
\hline 4 & $\begin{array}{l}\text { 1. Explicar os valores de voltagem apresentados por uma associação de pilhas ligadas em série e } \\
\text { de uma associação de pilhas ligadas em série com uma das pilhas ao contrário; } 2 \text {. Definir } \\
\text { operacionalmente circuitos elétricos (abertos e fechados), corrente elétrica, isolante e condutor } \\
\text { elétrico; } 3 \text {. Resolver exercícios que contemplem conceitos sobre: multímetro, voltagem, } \\
\text { amperagem, associação de pilhas em série e em paralelo, condutor, isolante, corrente elétrica e } \\
\text { circuito elétrico (aberto e fechado). }\end{array}$ \\
\hline 5 & $\begin{array}{l}\text { 1. Conceituar voltagem, amperagem, circuitos elétricos corrente elétrica, isolante e condutor } \\
\text { elétrico; } 2 \text {. Calcular a ddp de uma associação de pilhas em série com uma pilha ao contrário; } 3 \text {. } \\
\text { Diferenciar associação de pilhas em série e paralelo; } 4 \text {. Reconhecer os modelos atômicos de } \\
\text { Dalton, Thompson Rutherford e Niels Bohr; } 5 \text {. Relacionar a produção de corrente elétrica ao } \\
\text { movimento dos elétrons. }\end{array}$ \\
\hline 6 & $\begin{array}{l}\text { 1. Operar o multímetro na escala de resistência elétrica; } 2 \text {. Saber explicar a função dos } \\
\text { resistores; 3. Definir operacionalmente resistores, resistência elétrica e efeito Joule. }\end{array}$ \\
\hline 7 & $\begin{array}{l}\text { 1. Reconhecer fatores e/ou propriedades que influenciam na escolha de materiais resistivos; } 2 \text {. } \\
\text { Explicar o efeito da variação da temperatura, do comprimento e do diâmetro de um condutor na } \\
\text { resistência elétrica. }\end{array}$ \\
\hline 8 & $\begin{array}{l}\text { 1. Conceituar resistividade e resolver exercícios; } 2 \text {. Diferenciar resistência elétrica e } \\
\text { resistividade; } 3 \text {. Reconhecer e descrever fatores e/ou propriedades que influenciam na escolha } \\
\text { de materiais resistivos; } 4 \text {. Diferenciar propriedades específicas e gerais, material e substância. }\end{array}$ \\
\hline 9 & $\begin{array}{l}\text { 1. Resolver exercícios avaliativos e situações problemas utilizando os seguintes conceitos: } \\
\text { voltagem, amperagem, resistência elétrica; resistividade; circuito elétrico, corrente elétrica; } \\
\text { propriedades específicas/gerais e substância/material. }\end{array}$ \\
\hline \multicolumn{2}{|r|}{ UNIDADE 3 - MEIO AMBIENTE } \\
\hline Encontro & Objetivos de Ensino \\
\hline 10 & $\begin{array}{l}\text { 1. Discorrer sobre os impactos ambientais e danos ocasionados à saúde humana devido ao } \\
\text { descarte inadequado das pilhas e baterias. }\end{array}$ \\
\hline & UNIDADE 4 - SEGURANÇA NO TRABALHO \\
\hline
\end{tabular}




\begin{tabular}{|c|l|}
\hline Encontro & \multicolumn{1}{c|}{ Objetivos de Ensino } \\
\hline 11 & $\begin{array}{l}\text { 1. Identificar os riscos de acidentes com trabalhos que envolvem eletricidade; 2. Reconhecer EPI } \\
\text { e EPC de uso obrigatório, devido a possibilidade de ocorrência de choques elétricos e incêndios } \\
\text { em áreas energizadas; 3. Saber explicar reação química de combustão e diferenciar combustão } \\
\text { completa de incompleta; } 4 \text {. Identificar propriedades dos materiais e componentes dos EPI e EPC } \\
\text { e relacioná-las com o porquê da utilização destes equipamentos. }\end{array}$ \\
\hline
\end{tabular}

Fonte: Elaborado pelos autores (2020).

\section{Da análise da integração às decorrentes percepções e reflexões}

No início da intervenção buscou-se conhecer qual era o entendimento dos estudantes sobre o que seria um curso integrado, e os excertos de A7 e A25, que são representativos, mostraram desconhecimento deles sobre o EMI.

A7: Um curso que está acoplado ao Ensino Médio.

A25: Um curso junto com o Ensino Médio.

Essas e outras respostas evidenciaram que a compreensão predominante é a de que um curso integrado soma, em um só currículo, o Ensino Médio e o Ensino Técnico (profissionalizante), visando preparar os estudantes tanto para o ingresso em um curso superior, quanto para a inserção no mundo do trabalho. Cabe ressaltar que o somatório de disciplinas da formação básica e da formação específica no decorrer de um curso não é o mesmo que integração. Também, não é integração a simples adição de um ano de estudos profissionais a três do Ensino Médio (RAMOS, 2012).

A percepção do desconhecimento dos alunos sobre o EMI, levou a inserção de uma atividade para apresentar as diferenças entre a proposta de integração e a do Ensino Médio convencional. Quando a turma foi questionada sobre as expectativas quanto à integração a partir da disciplina de Química houve, por parte de alguns, resistência explicita, como denotam as respostas dos estudantes A5 e A28:

A5: [...] que eu aprenda os conceitos de forma que eu possa compreender a matéria do curso, mas sem prejudicar a matéria do ensino regular.

A28: [...] aprender o conteúdo cobrado no Enem que respectivamente é o ensino que devemos ter no segundo grau.

Tais respostas são representativas da resistência e evidenciam como os objetivos do ensino convencional e o direcionamento para os processos seletivos de acesso ao ensino superior estão presentes na mente dos alunos, o que pode estar relacionado a uma concepção arraigada na sociedade sobre essa etapa da formação escolar. $O$ desconhecimento dos estudantes sobre o EMI pode ser considerado como uma das prováveis causas da resistência inicial dos alunos.

Observa-se ainda, que alguns alunos, como A28, demonstraram interesse em estudar somente conteúdos cobrados em exames de acesso ao ensino superior. Em trechos escritos por A24 e A14, o desinteresse em aprender conceitos de Química integrados aos conhecimentos específicos da área de Eletrotécnica era evidente:

A24: Gostaria de saber como vamos repor essas aulas focadas em eletrotécnica nas aulas normais de química que acontecem em outras escolas.

A14: [...] não é porque nós estamos fazendo um curso técnico que nós estamos visando só o técnico, nós também visamos o vestibular onde é cobrada a Química do segundo grau, por isso eu gostaria de saber quando é que a matéria vai voltar. 
Pode-se identificar a resistência inicial à proposta associada à percepção de que trabalhar conteúdos de outras disciplinas atrapalharia o desenvolvimento dos de Química. A resistência também foi percebida pela professora regente da turma, que acompanhou todo o processo de intervenção e a apontou em seu relatório.

O desconhecimento dos alunos quanto aos objetivos do EMI, seus propósitos e a resistência inicial constituíram um desafio para o desenvolvimento da proposta e se considerou, conforme Machado (2009), que para a construção da integração seria de fundamental importância uma mudança de postura dos indivíduos envolvidos. Cada estudante foi questionado sobre a motivação pessoal que o levou a escolher o Instituição para cursar o ensino médio e suas respostas foram classificadas e agrupadas em três categorias na Tabela 1.

Tabela 1 - Motivação dos alunos para escolher a instituição para cursar o Ensino Médio.

\begin{tabular}{lcc}
\hline \multicolumn{1}{c}{ Categorias } & Número de alunos & Porcentagem \\
\hline $\begin{array}{l}\text { Ser uma escola federal, com ensino de qualidade e } \\
\text { com professores qualificados }\end{array}$ & 24 & $83 \%$ \\
Influência dos pais & 3 & $10 \%$ \\
Oferta do Ensino Médio junto com um curso técnico & 2 & $7 \%$ \\
\hline
\end{tabular}

Fonte: Elaborado pelos autores (2020).

Percebe-se que a maioria dos estudantes considera a instituição uma boa escola para concluir o nível médio, por ter um ensino de qualidade e professores qualificados. A qualificação docente foi um apontamento associado a um ensino de qualidade, o que demonstra reconhecimento social e, consequentemente, influencia na escolha da Instituição. No entanto, essa qualidade da instituição pode estar associada ao êxito dos estudantes em exames de acesso ao ensino superior e não, necessariamente, à preparação para o mercado de trabalho. Poucos ressaltaram a oferta do EMI como motivação para ingressar na Instituição, o que é compreensível, visto que desconheciam seus objetivos e princípios educacionais.

Quando questionados sobre a escolha do Técnico em Eletrotécnica Integrado ao Ensino Médio como área de formação, apenas $24 \%$ dos alunos usaram como justificativa o mercado de trabalho, como pode ser visto na Tabela 2.

Tabela 2 - Respostas dos alunos sobre o porquê da escolha do curso Técnico em Eletrotécnica Integrado ao Ensino Médio como área de formação.

\begin{tabular}{ccc}
\hline Respostas & Número de alunos & Porcentagem \% \\
\hline Afinidade com a área & 18 & 62 \\
\hline Mercado de trabalho & 7 & 24 \\
\hline Falta de opção & 3 & 10 \\
\hline Influência de amigos & 1 & 3 \\
\hline
\end{tabular}

Fonte: Elaborado pelos autores (2020).

Embora $62 \%$ tenham se referido como motivo para a escolha a afinidade com a área, a maioria não demonstrou conhecimento do que exatamente fazia um Técnico em Eletrotécnica. Não se pode deixar de levar em consideração que esses alunos fizeram a escolha de estar em um curso profissionalizante pelo menos três anos antes do que fariam ao concluir o ensino médio. Observa-se, também, que $24 \%$ dos alunos apontou como justificativa o mercado de trabalho. No entanto, somente um desses alunos, indicou como única escolha entrar no mercado de trabalho após a conclusão do EMI. 
Diante dos resultados, foi considerada a necessidade de que esses jovens conhecessem melhor atividades desenvolvidas pelo Técnico em Eletrotécnica. Neste caso, optou-se pelo debater o vídeo intitulado "Técnico em Eletrotécnica" " contendo algumas atividades, técnicas e materiais utilizados por esse profissional, bem como possíveis áreas de atuação. A produção audiovisual foi utilizada conforme orientações de Silva, Machado e Tunes (2010), com interrupções ao longo da exibição, para destacar informações relevantes, e com uma discussão sobre o tema, a partir de perguntas previamente definidas. Ao realizar tal discussão, percebeuse, da parte dos alunos, interesse em aprofundar o conhecimento sobre as áreas de atuação e o exercício da profissão de Técnico em Eletrotécnica. Diante disso, foi proposto que formassem grupos para elaborar produções audiovisuais respondendo às perguntas: 1. Como surgiu a profissão Técnico em Eletrotécnica? 2. O que faz um Técnico em Eletrotécnica? 3. Quais conhecimentos relacionados à Eletrotécnica serão importantes para sua formação? 4. Quais técnicas relacionadas à Eletrotécnica serão relevantes para sua formação? 5. Qual sua área de atuação? 6. Quais equipamentos/materiais são utilizados por esses profissionais? 7. Quais são as atividades deste Técnico dentro de uma empresa? Os vídeos produzidos foram apresentados no último encontro da intervenção e foram avaliados conforme critérios prédefinidos (motivação, criatividade e coerência nas ideias explicitadas), e todos contemplaram satisfatoriamente o objetivo de aprofundar o conhecimento sobre a profissão.

Conforme definido na proposta didática, na Unidade 2 foi trabalhada a temática medições elétricas, considerando a sua relevância para o exercício profissional do Técnico em Eletrotécnica e as possibilidades de integração de conteúdos de várias disciplinas no seu desenvolvimento. Assim, o Quadro 2 apresenta um sumário das estratégias e recursos utilizados tendo em vista promover a integração.

Quadro 2 - Estratégias e recursos utilizados em oito encontros para trabalhar definições operacionais e conceitos relativos à temática medições elétricas.

\begin{tabular}{|c|c|}
\hline \multicolumn{2}{|r|}{ UNIDADE 2 - MEDIÇÕES ELÉTRICAS } \\
\hline $\begin{array}{c}\text { Encontro } \\
\mathrm{S}\end{array}$ & Estratégias / Recursos \\
\hline 1 & $\begin{array}{l}\text { I. Análise de imagens para identificar a familiarização dos estudantes com materiais e técnicas } \\
\text { inerentes à profissão do Técnico em Eletrotécnica. Vídeo disponível em: } \\
\text { https://www.youtube.com/watch?v=bbXjzED4gTg. } \\
\text { II. Levantamento dos conhecimentos prévios dos estudantes, por meio de questionamento oral, } \\
\text { sobre voltagem e amperagem. } \\
\text { III. Apresentação em slide, sobre a utilização do multímetro em testes de medições elétricas. } \\
\text { IV. Realização de experimento demonstrativo de medição elétrica em pilhas e tomadas, para } \\
\text { explorar as funcionalidades do multímetro. } \\
\text { V. Discussão das definições operacionais para as grandezas amperagem e voltagem. }\end{array}$ \\
\hline 2 & $\begin{array}{l}\text { Realização de atividade experimental, em grupos, para exploração e manuseio do multímetro } \\
\text { pelos alunos, incluindo: } \\
\text { - medição de voltagens de pilhas em diferentes estados de uso; } \\
\text { - medição de voltagem de duas baterias; } \\
\text { - aferição de voltagem e amperagem de pilhas associadas em série e em paralelo; } \\
\text { - observação da intensidade do brilho de lâmpadas conectadas aos circuitos; } \\
\text { - discussão de aspectos operacionais e conceituais ao longo da atividade. }\end{array}$ \\
\hline 3 & $\begin{array}{l}\text { I. Realização de atividade experimental, em grupos de alunos, para desenvolver conceitos de } \\
\text { corrente elétrica, circuito aberto, circuito fechado e condutividade. } \\
\text { II. Exposição dialogada realizada pela professora, para desenvolver conceitos de corrente e } \\
\text { circuito elétrico, com utilização de vídeo "Explaining an Electrical Circuit" - disponível em: } \\
\text { https://www.youtube.com/watch?v=VnnpLaKsqGU. } \\
\text { III. Realização de avaliação da aprendizagem dos conteúdos trabalhados. }\end{array}$ \\
\hline
\end{tabular}

\footnotetext{
${ }^{7}$ Disponível em: https://www.youtube.com/watch?v=bbXjzED4gTg
} 


\begin{tabular}{|c|l|}
\hline 4 & $\begin{array}{l}\text { Revisão dos conceitos não compreendidos pelos estudantes, por meio de discussão oral e } \\
\text { realização de exercícios associados a um estudo de caso sobre medições elétricas. }\end{array}$ \\
\hline 5 & $\begin{array}{l}\text { I. Apresentação em slides para iniciar o estudo da grandeza resistência elétrica. } \\
\text { II. Explicação oral sobre o funcionamento dos resistores, suas funcionalidades nos circuitos } \\
\text { elétricos e ofeito Joule. } \\
\text { III. Realização de atividade experimental, em grupos de alunos, para investigar as condições de } \\
\text { uso de duas lâmpadas, sendo uma queimada e outra não, por meio do teste das resistências } \\
\text { elétricas de ambas. }\end{array}$ \\
\hline 6 & $\begin{array}{l}\text { I. Realização de atividade experimental, em grupos de alunos, para investigar fatores que } \\
\text { influenciam a resistência elétrica: comprimento e diâmetro de um condutor. } \\
\text { II. Elaboração de gráficos, pelos alunos, Resistência X Comprimento e Resistência X Diâmetro, } \\
\text { com os valores coletados na investigação experimental. } \\
\text { III. Discussão, por meio de gráficos, sobre a influência da temperatura na resistência elétrica. }\end{array}$ \\
\hline 7 & $\begin{array}{l}\text { I. Realização de atividade experimental, em grupos de alunos, para investigar características e } \\
\text { propriedades do cobre e do grafite e diferenciar os conceitos de propriedade específica e geral; } \\
\text { material e substância; resistência e resistividade. } \\
\text { II. Utilização de um Simulador de Circuito, disponibilizado pela University of Colorado Boulder } \\
\text { para aprofundar os estudos sobre resistividade. Disponível em: } \\
\text { https://phet.colorado.edu/pt_BR/simulation/circuit-construction-kit-dc-virtual-lab. }\end{array}$ \\
\hline 8 & Realização de avaliação da aprendizagem dos conteúdos trabalhados. \\
\hline
\end{tabular}

Fonte: Elaborado pelos autores (2020).

Em decorrência do questionamento sobre o que os estudantes entendiam por voltagem e amperagem (Encontro 1 - Unidade 2), os excertos das falas de A10 e A16 são representativos do entendimento predominante na turma:

A10: Amperagem é a grandeza que mede a corrente elétrica.

A16: Voltagem é a diferença de potencial.

Tais colocações, apesar de evidenciarem que a maioria dos estudantes já possuía algum conhecimento relacionado a essas grandezas, demonstraram que, naquele momento, o conceito de amperagem vigente não era suficiente para o manuseio adequado do multímetro. A partir disso, foram retomadas as explicações e apresentadas as definições operacionais sobre tais grandezas, para que em um momento oportuno, pudesse ser retomado os conceitos, agregando a ótica da Ciência.

Ao longo da realização das atividades experimentais, nos encontros 1, 2 e 3, muitos estudantes continuavam não apresentando desenvoltura suficiente para utilizar o multímetro, sendo necessário auxiliá-los, de forma recorrente, na execução das medições e alertá-los quanto à posição correta da chave seletora e quanto ao uso adequado das ponteiras de prova. Com isso, deduz-se que, apesar dos alunos já terem trabalhado com o equipamento na disciplina Circuitos Elétricos, conforme informado pelo professor em entrevista, restavam dúvidas sobre definições e conceitos básicos. Por exemplo, ao serem perguntados o que eram os dispositivos ligados aos fios vermelho e preto, prontamente, os identificaram como positivo e negativo e não como ponteiras de prova. Tal fato reforçou a necessidade de se continuar trabalhando na perspectiva da interdisciplinaridade, desenvolvendo em uma mesma técnica conteúdos diversificados, de forma a possibilitar a integração pretendida.

No desenvolvimento de todas as Unidades, foi utilizada, ao final de cada encontro, uma ficha de avaliação, instrumento que permitiu à professora avaliar se os objetivos propostos estavam sendo alcançados e identificar as fragilidades apresentadas, em relação ao conteúdo. A ficha compreendia as seguintes perguntas: 1. O que você aprendeu nessa aula? 2. O que você não aprendeu nessa aula? 3. Como você avalia essa aula de 0 a 5 . Havia, ainda, um campo destinado a inserção de observações. Essa avaliação permitiu acompanhar, em tempo real, o processo ensino-aprendizagem, retomando, na aula seguinte, o que não havia 
sido adequadamente compreendido na anterior, evitando o acúmulo de dúvidas. Alguns trechos das respostas dos alunos à primeira (A16, A18, A22 e A29) e à segunda (A15, A24, A27) perguntas das fichas são destacadas, em relação aos encontros da Unidade 2.

- Resposta à Pergunta 1:

A16: Consegui aprender tudo, principalmente diferença de grandeza com unidade.

A18: Usar o multímetro na prática. As relações entre o tipo de circuito, a amperagem e a voltagem e como isso influencia no brilho da lâmpada no circuito.

A22: Aprendi o que é amperagem e voltagem. Também aprendi a usar um multímetro para medir tensão e correntes em tomadas, pilhas e baterias.

A29: Aprendi a classificar as pilhas em boa, fraca ou exaurida analisando com o multímetro...

- Resposta à Pergunta 2:

A15:Como se calcula a tensão de duas pilhas associadas em paralelo.

A24: Não aprendi o que é tensão.

A27: Como fazer a conta para saber a voltagem da pilha.

Abaixo, encontram-se reproduzidos trechos de algumas percepções dos estudantes sobre as aulas no campo destinado às observações:

A8: A aula foi interativa, o que foi ótimo.

A14: O conteúdo foi bem explicado. Portanto, compreendi o que foi passado e aumentei meu conhecimento. Gostei da aula prática.

A19: Hoje a aula foi muito boa, foi mais interessante que o normal.

Esses apontamentos mostraram que a estratégia de desenvolver atividades experimentais em grupo foi adequada para promover o interesse dos alunos e, por meio das interações professor-aluno e aluno-aluno, no decorrer dos experimentos, a aprendizagem.

Durante um dos experimentos da Unidade 2, o aluno A2 questionou à professora sobre o funcionamento das pilhas recarregáveis. A resposta buscou adequar-se ao nível de compreensão da turma que, por ser do primeiro ano, ainda operam no nível macroscópico. Sendo assim, a resposta compartilhada com o restante da turma mostrou que na pilha recarregável ocorrem reações químicas reversíveis (BOCCHI; FERRACIN; BIAGGIO, 2000). A dúvida de A2 mostrou seu interesse para além de executar a técnica, ele buscou conhecer as explicações da Ciência para os fenômenos correlacionados à atividade, o que contempla a perspectiva politécnica. Isso pode ser tomado como indicativo de avanço na consecução do objetivo de possibilitar a integração tendo o trabalho como princípio educativo.

Ao final do terceiro encontro da Unidade 2 foi realizada a Avaliação I com o objetivo de investigar que conexões entre as definições operacionais e os conceitos científicos de amperagem e voltagem os estudantes conseguiam fazer por meio do manuseio do multímetro. A análise dos resultados mostrou que alguns alunos não compreenderam a diferença entre Volts e voltagem, Amper e amperagem e também apresentaram dúvidas sobre o conceito das grandezas físicas estudadas. Após revisão desses conceitos foi aplicada a Avaliação II, 
constatando-se que os alunos conseguiram resolver suas dúvidas em relação às unidades de medida (Volts e Amper) e às grandezas físicas (voltagem e amperagem).

$\mathrm{Na}$ Avaliação II foi perguntado que outras grandezas poderiam ser medidas pelo multímetro, ao que A9, A11, A14, A17, A18, A23 e A29 indicaram a resistência elétrica, antes mesmo dela ser abordada nas aulas. A resistência elétrica já tinha sido objeto de estudo na disciplina de Circuitos Elétricos. Outra observação realizada após a Avaliação II foi o fato de A3, A16 e A26 apontarem a resistividade como uma grandeza física medida pelo multímetro. Como a resistividade é uma propriedade específica de um determinado material e/ou substância, não pode ser medida pelo multímetro. Apesar disso, os estudantes se saíram melhor na segunda avaliação, demonstrando que rever os conceitos foi uma medida acertada.

No sétimo encontro da Unidade 2, ao estudar a grandeza resistência elétrica percebeuse maior familiaridade dos alunos com o multímetro e com as ponteiras de prova, enquanto realizavam testes de resistência do cobre e do grafite. Os valores de resistência medidos levaram os alunos concluírem que o cobre é um melhor condutor do que o grafite. Somente alguns relataram que a diferença de resistência estaria associada à composição das substâncias. A não compreensão sobre o conceito de resistência de alguns, levou a intervenção da professora pesquisadora em cada grupo para relacionar a estrutura de uma substância ou material com sua oposição à passagem de corrente elétrica e a relação com a resistência elétrica. $\mathrm{O}$ conceito de resistividade foi retomado utilizando-se um Simulador de Circuito, citado no Quadro 2. A atividade despertou grande interesse dos alunos, corroborando com Macedo, Dickman e Andrade (2012, p. 609) sobre o uso de simulações proporcionar um ambiente de estímulo, motivação e envolvimento, melhorando o processo ensino-aprendizagem, desde que explorado adequadamente pelo professor.

Ao final da Unidade 2, foi aplicada a Avaliação III e, com a correção da primeira foi possível perceber que $72 \%$ da turma já compreendia a resistência elétrica como uma propriedade que não permite identificar um metal e que propriedades como resistividade, ponto de fusão e densidade ajudam identificar uma substância.

Nessa mesma avaliação, por meio da questão 2 , foi possível observar que somente oito alunos (28\%) conseguiram compreender a relação de proporcionalidade entre as grandezas resistividade e temperatura. Entre os demais, doze (41\%) não conseguiram entender que ao aumentar a temperatura há maior probabilidade de ocorrer mais choques entre os elétrons livres e os átomos do condutor. Os outros nove alunos (31\%) mostraram dúvidas sobre essa relação. Uma possível explicação para a dificuldade apresentada pelos estudantes é o fato de não ter sido trabalhado experimentalmente a relação temperatura e resistividade. De acordo com Silva, Machado e Tunes (2010), as atividades experimentais favorecem a superação da dicotomia entre fenômeno e teoria e auxiliam o aprendiz na construção de abstrações, relações e inferências. Além disso, podem possibilitar o estabelecimento de relações entre conhecimentos de diversas áreas; o desenvolvimento das funções psíquicas superiores (VIGOTSKI, 2000) e de uma postura mais ativa dos alunos, ao realizarem atividades investigativas (OLIVEIRA, 2010).

$\mathrm{Na}$ terceira questão, havia um pequeno texto falando sobre a lâmpada incandescente e foi solicitada uma descrição do teste de resistência elétrica para avaliar o estado de uso de uma lâmpada, conteúdo trabalhado no encontro 5 da Unidade 2. Quatro alunos (14\%) conseguiram descrever corretamente o teste de verificação do estado de uso da lâmpada através do multímetro, porém equivocaram-se ao dizer que a lâmpada queimada apresenta resistência igual a zero, como podemos observar na resposta de A24: 
A24: Com a chave do multímetro ligada na resistência, deve-se conectar as ponteiras de prova vermelha no pólo positivo e a preta no negativo. Se sua resistência foi $0 \Omega$, a lâmpada está queimada.

A resposta de A4 mostra que ele não conseguiu compreender o teste de medição de resistência elétrica. Assim como A4, outros 7 alunos (24\%) não indicaram a resistência elétrica como a grandeza a ser selecionada no multímetro para avaliar o estado de uso de uma lâmpada.

A4: Eu coloco a chave seletora do multímetro em A (corrente elétrica) contínua e coloco as ponteiras de prova, a positiva na parte positiva da lâmpada e a negativa na parte negativa da lâmpada.

Nessa atividade, ainda foi avaliado o que os alunos entenderam sobre a voltagem de pilhas associadas em série e em paralelo. Este conteúdo foi trabalhado nas primeiras aulas da proposta e $90 \%$ dos alunos relacionaram a diferença dos valores apresentados no multímetro à associação de pilhas em série e paralelo. Os estudantes também souberam relatar o significado qualitativo da grandeza voltagem conforme se vê na resposta de A19.

A19: A grandeza medida é voltagem, que mede a diferença de potencial entre as pilhas A e B. No caso, quando ligadas em paralelo, sua diferença de potencial é menor do que quando ligada em série.

Como o curso em que essa proposta foi desenvolvida tem por objetivo formar Técnicos em Eletrotécnica, há destacada relevância trabalhar questões ambientais e sociais inerentes ao exercício da profissão (Quadro 3), bem como, desenvolver a capacidade de análise das inter-relações CTS associadas ao processo produtivo, visando, a formação omnilateral dos indivíduos com base na integração de todas as dimensões da vida (RAMOS, 2007).

Quadro 3 -Estratégias e recursos utilizados para trabalhar os impactos sociais e ambientes dos artefatos tecnológicos pilhas e baterias.

\begin{tabular}{|c|c|}
\hline \multicolumn{2}{|r|}{ UNIDADE 3 - MEIO AMBIENTE } \\
\hline Encontro & Estratégias/Recursos \\
\hline 1 & $\begin{array}{l}\text { I. Investigação oral com os alunos sobre o tipo de pilha comumente usada (alcalina ou } \\
\text { comum) e o descarte final desse dispositivo. } \\
\text { II. Utilização do texto intitulado "Pilhas, baterias e seus impactos" para trabalhar o descarte } \\
\text { adequado de pilhas e baterias. } \\
\text { III. Explicação sobre a diferença da composição química dos tipos de pilhas. } \\
\text { IV. Apresentação e discussão dos conceitos de oxidação, íons, biodegradação e } \\
\text { bioacumulação. }\end{array}$ \\
\hline
\end{tabular}

Fonte: Elaborado pelo autor (2020).

Os alunos foram questionados sobre o descarte adequado das pilhas exauridas. Por meio da análise das filmagens das aulas foi possível captar a resposta de A19 "jogo no lixo" e de A5 "Eu jogo no lixo comum, mas sei que isso não é correto". Essas respostas expõem um sério problema em nossa sociedade, a falta de informação sobre o descarte correto de pilhas e baterias e a imprudência em relação às normas relacionadas aos riscos à saúde e ao ambiente que a disposição inadequada pode ocasionar.

Na perspectiva de contribuir para evitar atitudes como as reveladas pelas respostas de A5 e A19, foi trabalhado com os estudantes o tema descarte de pilhas, baterias e suas consequências ambientais. Faz parte da formação integral refletir criticamente com os alunos questões implícitas à prática profissional, mas que nem sempre são compreendidas eticamente. A problemática relativa aos resíduos eletroeletrônicos é uma discussão imprescindível a ser realizada com alunos deste curso, visto que, no currículo que integra 
formação geral, técnica e política, a cidadania e o trabalho não são separados em universos distintos, mas devem comungar de um mesmo ideal, a formação integral (RAMOS, 2011).

Dando continuidade às discussões, foi perguntado qual tipo de pilha era usada pelos estudantes, alcalina ou comum. As respostas da maioria, representadas abaixo por A14 e A28, mostraram desconhecimento sobre a diferença entre os dois tipos de pilha.

A28: Eu não sei a diferença, mas eu compro sempre a mais barata.

A14: Eu compro a que o vendedor me oferecer.

Essas respostas evidenciam que as escolhas destes alunos são realizadas sem uma análise dos fatores relevantes para um consumo consciente, dentre eles, questões técnicas, econômicas e ambientais. Para contribuir com tal análise, foi discutida a maior capacidade de descarga das pilhas alcalinas primárias que, por isso, superam o desempenho da pilha Leclanché. Além disso, foi debatida, a partir da leitura de um texto elaborado tendo como referência Bocchi, Ferracin e Biaggio (2000), a baixa ocorrência de reações paralelas nas pilhas alcalinas, também conhecidas como reações de prateleira. Foi explicado que a minimização de tais reações se deve a presença de substâncias com íons mercúrio, chumbo e cádmio, que contribuem para diminuição de vazamentos comumente observados nas pilhas de Leclanché. Foi discutido com os estudantes o fato do maior custo das pilhas alcalinas está relacionado ao investimento realizado para melhorar não somente o desempenho delas, mas também para minimizar o percentual de metais tóxicos, tornando-as menos impactante ambientalmente.

A leitura do texto serviu também para trabalhar conceitos como reações de oxidação, espécies iônicas, biodisponibilização, biodegradação e bioacumulação e sua relação com a poluição ambiental. Ao final das atividades, ao responderam à pergunta 1 da ficha de avaliação ficou evidente que há clara integração entre os conhecimentos científicos (trechos sublinhados) e as definições operacionais (trechos em negrito), além de uma maior compreensão sobre a composição das pilhas, seu descarte inadequado e a poluição ambiental.

A19: [...] sobre os efeitos causados pelos elementos presentes nas pilhas e baterias.

A26:Como funciona o descarte correto das pilhas; o que é íons; o que é bioacumulativos.

\section{A28: Os efeitos do descarte de pilhas no lixo.}

$\mathrm{Na}$ Unidade 4, foi realizado um único encontro, para abordagem sobre acidentes de trabalho, envolvendo incêndios e choques elétricos, relacionando-os com o uso e propriedades dos Equipamentos de Proteção Individual (EPI) e Proteção Coletiva (EPC) que devem ser utilizados por Técnicos em Eletrotécnica. Enfatizamos, também, as reações químicas de combustão e a diferença entre combustível e comburente. O Quadro 4 expõe as estratégias e recursos utilizados nesse encontro.

Quadro 4 - Estratégias e recursos utilizados para trabalhar definições operacionais e conceitos relativos à temática segurança no trabalho.

\begin{tabular}{|c|l|}
\hline \multicolumn{2}{|c|}{ UNIDADE 4 - SEGURANÇA NO TRABALHO } \\
\hline Encontro & \multicolumn{1}{c|}{ Estratégias/Recursos } \\
\hline \multirow{3}{*}{1} & $\begin{array}{l}\text { I. Discussão, a partir do vídeo "Choque Elétrico", sobre acidentes de trabalho na profissão de } \\
\text { Técnico em Eletrotécnica, envolvendo incêndios e choques elétricos, o uso e as propriedades } \\
\text { dos EPI e dos EPC. (Disponível em: https://www.youtube.com/watch?v=usLEVgJwyss). } \\
\text { II. Apresentação dos conceitos de combustão e choque elétrico (conhecimentos científicos), } \\
\text { levando em consideração os acidentes de trabalho discutidos no vídeo. } \\
\text { III. Apresentação e explicação sobre o triângulo do fogo, identificando os elementos necessários } \\
\text { para a ocorrência de incêndios envolvendo fontes energizadas. }\end{array}$ \\
\hline
\end{tabular}


\begin{tabular}{|l|l|}
\hline & $\begin{array}{l}\text { IV. Discussão sobre as reações de combustão completa e incompleta, destacando as classes de } \\
\text { incêndio A, B e C e relacionando-as aos tipos de extintores, tomando como base as } \\
\text { propriedades dos materiais incendiados. }\end{array}$ \\
\hline
\end{tabular}

Fonte: Elaborado pelos autores (2020).

Nesse encontro, os alunos realizaram uma atividade, na qual tinham que descrever uma situação em que ficasse evidente relações da Química com a Eletrotécnica. O destaque foi dado para as respostas dos alunos A5, A19, A23 e A28:

A5: O que pode acontecer quando uma corrente passa por nosso corpo? O que tem em uma pilha, como e por que ela acaba? Tudo isso aprendemos relacionando Química com a eletrotécnica. Isso podemos ver quando acontece as reações químicas, onde está evidente o acontecimento. E tudo o que aprendemos não é ensinado no ensino médio normal. Tudo o que aprendemos até hoje será necessário para o resto de nossas vidas.

A19: Antes eu não relacionava a química com a eletrotécnica em si, pensava que eram duas coisas distintas. Mas hoje, depois das aulas integradas, percebi que a química se relaciona diretamente a eletrotécnica. No caso, um exemplo claro, seriam as reações químicas que ocorrem dentro da pilha. Outro exemplo seria em qual caso utilizar qual instintor. Pois cada instintor tem seu uso específico para determinada situação. (sic)

A23: A química tem clara presença no dia a dia de um técnico em eletrotécnica, já que alguns materiais que eles usam tem reações químicas, como pilhas, baterias entre outras coisas e também pode se falar dos materiais já que eles tem que escolher para fazerem fios por exemplo como cobre, prata, ouro entre outros e a quimica pode estar presente até na energia por exemplo ou seja a química é bem importante para um eletrotécnico. (sic)

A28: A Química é muito importante para o técnico em Eletrotécnica, é importante para ele ter conhecimentos químicos, como composição de materiais, para saber qual material conduz melhor, qual pode ser mais isolante qual apresenta maior resistência. Portanto conhecimentos químicos são importantes para o técnico conhecer melhor com o que ele está trabalhando.

Nos trechos destacados fica evidente o reconhecimento dos estudantes sobre a importância de se compreender os fundamentos científicos relacionados às técnicas profissionais da área do Técnico em Eletrotécnica, ao relatarem o uso de extintores específicos para cada caso de incêndio, a escolha de materiais para compor um fio elétrico e as reações químicas que ocorrem nas pilhas.

Outro ponto a ser considerado é que, apesar da resistência inicial de alguns alunos quanto à integração, na avaliação final, há um reconhecimento da sua importância para aqueles que querem ser profissionais da área, inclusive de A5. Aqui, evidencia-se a defesa de Machado (2009); Moura (2013) e Ramos (2011) sobre o EMI possibilitar ao estudante uma formação para o exercício crítico da cidadania, para a empregabilidade e para o acesso ao nível superior de formação. Isso permite que se fuja do determinismo decorrente da dualidade das propostas anteriores, oportunizando ao educando que ele escolha seus caminhos formativos e profissionais.

Durante a intervenção, surgiram várias dificuldades. Identificá-las permitiu adequar planejamentos e posturas, para avançar no processo em conformidade com as diretrizes e propósitos iniciais. Tais dificuldades e adequações estão sintetizadas no Quadro 5. 
Quadro 5 - Síntese das dificuldades e adequações vivenciadas no processo.

\begin{tabular}{|l|l|}
\hline Dificuldade & Adequação \\
\hline Adequação do tempo da aula ao planejamento. & Readequação de atividades previstas nos planos de aula. \\
\hline Não cumprimento da Tarefa de Casa pelos alunos & $\begin{array}{l}\text { Replanejar as tarefas de casa e chamar atenção dos alunos } \\
\text { para a importância da tarefa de casa no processo de } \\
\text { ensino-aprendizagem. }\end{array}$ \\
\hline $\begin{array}{l}\text { Planejamento de aulas com integração de } \\
\text { conhecimentos específicos e de Química }\end{array}$ & $\begin{array}{l}\text { Busca de novos conhecimentos, inclusive de outras áreas. } \\
\text { Elaboração e desenvolvimento de estratégias e } \\
\text { metodologias ainda não praticadas pela professora. }\end{array}$ \\
\hline $\begin{array}{l}\text { Desenvolvimento de proposta que tem o trabalho } \\
\text { como princípio educativo. }\end{array}$ & $\begin{array}{l}\text { Discussões e reflexões sobre os objetivos do EMI e sua } \\
\text { diferenciação em relação ao Ensino Médio convencional }\end{array}$ \\
\hline $\begin{array}{l}\text { Planejamento de aulas contemplando a associação } \\
\text { entre teoria e atividade experimental }\end{array}$ & $\begin{array}{l}\text { Realizaçáo de novas estratégias didáticas que } \\
\text { favorecessem a associação entre teoria e atividade } \\
\text { experimental. }\end{array}$ \\
\hline
\end{tabular}

Fonte: Elaborado pelos autores (2020).

O fator tempo sempre se apresentou como um desafio. Muitas vezes, a vontade de um professor responder a perguntas e dar atenção a todos leva a extrapolação do tempo previsto para cada atividade e há necessidade de readequação do planejamento. Percebeu-se que, em se tratando de sala de aula, é preciso considerar que as atividades planejadas no papel "ganham vida", ao serem executadas. Por isso, uma atividade com duração planejada para 10 minutos pode se tornar uma aula de 50 minutos. Isso está relacionado à dinâmica e a particularidade de cada turma e, também, de cada aula, pois a interação dos alunos com o conteúdo, incluindo aí as dúvidas, as discussões suscitadas, a maior ou menor dificuldade na realização de atividades, pode ser maior em uma aula e menor em outra. Enfim, várias são as situações que surgem durante uma aula, ocasionando que ela não ocorra como planejada. O importante é identificar os pontos que requerem adequações e realizá-las o mais brevemente possível, no decorrer do processo.

Através dessa proposta didática, foi possível perceber quão desafiador é para alunos e professores desenvolver várias atividades e estratégias em pouco tempo. O processo de ensino-aprendizagem requer tempo para compreensão, raciocínio e reflexão, por parte de todos. Abordar muitos conteúdos e/ou atividades em um curto espaço de tempo não é uma estratégia efetiva para o aprender e nem para o ensinar. Aulas muito "sobrecarregadas" de conteúdos e atividades não permitem ao aluno apropriar-se de tudo aquilo que lhe está sendo proposto.

Outra dificuldade identificada no processo de intervenção está relacionada à realização das tarefas de casa pelos estudantes, visto que poucos entregaram as tarefas. Tais atividades são fundamentais para a avaliação individual da aprendizagem do conteúdo visto em aula, para o levantamento de dúvidas e para a consolidação do conhecimento. A tarefa de casa possibilita ao professor explorar aspectos atitudinais como responsabilidade e compromisso. Nesse sentido, ela se justifica a partir de fatores psicológicos e morais, sendo considerada um importante instrumento no desenvolvimento da independência, da autonomia e da responsabilidade do discente, auxiliando-o no compromisso diário com os estudos (FUJIMOTO; MARTINS, 2013). Dentre os argumentos para não entrega das tarefas estava a falta de tempo ou o esquecimento. Ambos mostravam falta de planejamento e organização, aspectos que devem ser trabalhados pela família e pela escola, nos processos formativos. Esses pretextos podem ser uma forma de não deixar transparecer a ausência de hábitos de estudo em casa, ou o descompromisso com o estudo diário. Mas aqui cabe considerar que esses alunos tinham uma elevada carga horária escolar, visto cursavam 19 disciplinas, 
perfazendo um total de 32,5 horas semanais de aula. Diante de tais ponderações o número de questões foi reduzido e houve um aumento de entrega da tarefa. A utilização de subterfúgios pelo estudante para não realizar a tarefa de casa demonstra quão fundamental é o professor explicar-lhes a importância dessa atividade para o processo ensino-aprendizagem.

Uma das maiores dificuldades vivenciadas neste processo foi elaborar aulas integrando conhecimentos de Química aos de outras áreas, como por exemplo, Física. Na busca por promover a integração, foram planejadas estratégias envolvendo resolução de problemas e desafios (RAMOS, 2014), com situações com as quais os alunos provavelmente se defrontariam no exercício da profissão de Técnico em Eletrotécnica. Isso sem perder o cuidado de adequar os conteúdos e atividades à turma de primeiro ano. $\mathrm{O}$ recurso utilizado foi adotar definições operacionais quando os conceitos correspondentes apresentavam maior complexidade e demandavam conteúdos ainda não estudados. Essa diretriz assumida para a efetivação da integração nos exigiu conhecer procedimentos operacionais da técnica que seria abordada e outros aspectos a ela associados, como implicações sociais, ambientais e comportamentais.

Exigiu, ainda, que os conhecimentos de Química e de outras disciplinas que a fundamentavam ou a ela se relacionavam fossem previamente conhecidos. Assim, a revisão cuidadosa dos planos de aula elaborados, a reconstrução de atividades, novos conhecimentos, estratégias e metodologias de ensino foram constantes durante todo o processo. A diretriz assumida pela professora, para superar a quarta dificuldade mencionada no Quadro 5, foi realizar constantes intervenções relembrando aos discentes os objetivos do EMI e em que ele se diferencia do Ensino Médio convencional.

Ao final do desenvolvimento da proposta didática, os 29 alunos avaliaram, de forma anônima, os recursos e/ou as atividades realizadas. As respostas mostraram que a maioria avaliou como "excelente" ou "muito bom" as atividades experimentais e as discussões ocorridas. Dentre as atividades experimentais, a unanimidade foi a "energy ball", que tinha por objetivo investigar e discutir os conceitos de corrente elétrica, circuito aberto, circuito fechado e condutividade. Entendemos que a metodologia utilizada pelo professor para ensinar um determinado conteúdo pode tanto motivar, atrair e estimular o aluno no processo de aprendizagem, quanto tornar a aula monótona e desestimulante. Assim, destaca-se a importância de se dedicar, no planejamento da aula, uma atenção especial à metodologia a ser utilizada, que deve levar em consideração os objetivos estabelecidos, os recursos e estrutura organizacional disponíveis, o perfil da turma, dentre outros fatores.

\section{Considerações Finais}

A percepção da falta de articulação entre conhecimentos da base geral, como a Química, com conhecimentos da base específica - isto é, as matérias profissionalizantes, em um curso de Ensino Médio Integrado à Educação Profissional de um Instituto Federal -, motivou as professoras envolvidas a desenvolver e investigar uma proposta didática para os alunos do curso Técnico em Eletrotécnica, com o objetivo de promover a integração em perspectiva politécnica.

\footnotetext{
${ }^{8}$ Trata-se de uma esfera que traz internamente um circuito simples aberto e, externamente, existem dois sensores que, quando tocados com dois dedos, simultaneamente, promovem o fechamento do circuito, fazendo uma luz vermelha acender, devido ao fluxo de elétrons através do corpo ou de outro material condutor usado. (Informações disponíveis em: http://blog.teachersource.com/2009/12/30/the-energy-ball/).
} 
O primeiro passo na busca por responder à questão "Como promover a integração, em perspectiva politécnica, entre a Química e disciplinas específicas no curso Técnico em Eletrotécnica ofertado de forma Integrada?" passou por estudar detalhadamente o PPC do referido curso, além de consultar professores da área específica para identificar e selecionar as disciplinas cujos conteúdos serviriam de ponto de partida para o desenvolvimento da proposta. Após essa etapa, foram elaboradas, desenvolvidas e, posteriormente, analisadas as estratégias didáticas voltadas para a efetivação da integração em perspectiva de uma formação politécnica.

A proposta didática, desenvolvida em quatro unidades, abordou a temática "Medições elétricas, meio ambiente e segurança no trabalho", através da qual, foram trabalhadas técnicas profissionais vivenciadas no cotidiano do Técnico em Eletrotécnica, por meio das definições operacionais e dos conceitos científicos (amperagem, voltagem, resistência elétrica, choque elétrico, corrente elétrica, incêndio, descarte de resíduos eletroeletrônicos etc.). Para isso, foram utilizadas ferramentas importantes para o trabalho desse profissional, como o multímetro, os EPI e EPC. A ideia foi levar para a sala de aula diferentes recursos e estratégias didáticas, em que os aspectos manuais e intelectuais fossem trabalhados de forma indissolúvel.

Um aspecto a ser considerado refere-se à percepção desenvolvida das pesquisadoras, ao longo do processo, de que a interdisciplinaridade, inerente à integração, poderia ter sido melhor explorada com uma maior participação dos professores das disciplinas envolvidas nas diversas etapas da proposta, ao invés de apenas no momento inicial, de definição das disciplinas e conhecimentos estruturantes a serem trabalhados nas aulas de Química. Assim, aponta-se que o trabalho conjunto com os docentes que atuam no EMI pode levar ao desenvolvimento de propostas nas quais a integração, em perspectiva politécnica, se efetive como uma diretriz institucional, indo além de uma ação pontual ou projeto isolado.

A partir das reflexões sobre os avanços vivenciados e as possibilidades identificadas neste processo, pode-se inferir que a metodologia desenvolvida na proposta didática mostrou resultados promissores com relação à integração entre os conhecimentos das disciplinas citadas, além de ter possibilitado uma melhor compreensão, por parte dos alunos, dos princípios e propósitos do Ensino Médio Integrado. Alguns deles foram capazes de expor claramente como os conhecimentos da Química não só estão relacionados aos conhecimentos técnicos, como também são os fundamentos destes. Assim, em relação à pergunta norteadora do trabalho, afirma-se que a integração dos conteúdos das disciplinas envolvidas pode ser efetivada tendo como contexto um tema inerente à atuação profissional e pelo desenvolvimento de metodologias variadas e dinâmicas, notadamente aquelas de caráter investigativo e discursivo.

Por fim, é pertinente apontar que as discussões realizadas nesse trabalho têm potencial para subsidiar abordagens em uma área ainda pouco explorada: a formação de professores para a atuação na Educação Profissional integrada ao Ensino Médio. Julgamos que esse estudo pode contribuir para a reestruturação de programas de formação inicial de professores de Química, no sentido de proporcionar aos licenciandos oportunidades de: (a) conhecer a história do EMI, assim como suas concepções, princípios e propósitos; (b) conhecer, trabalhar com, e desenvolver materiais que sejam adequados à integração na perspectiva da politecnia; (c) vivenciar ambientes de integração e refletir sobre essas experiências; e (d) aplicar seus conhecimentos pedagógicos relativos à integração no desenvolvimento de estratégias de ensino que a favoreçam. 


\section{Referências}

BRAIBANTE, M. F.; PAZINATO, M. S. O Ensino de Química através de temáticas: contribuições do LAEQUI para a área. Ciência e Natura, v. 36, p. 819-826, 2014.

BOCCHI, N.; FERRACIN, L. C.; BIAGGIO, S. R. Pilhas e baterias: funcionamento e impacto ambiental. Química Nova na Escola, n. 11, p. 3-9, 2000.

BOGDAN, R. C.; BIKLEN, S. K. Investigação Qualitativa em Educação: uma introdução à teoria e aos métodos. 12 ed. Porto: Porto Editora, 2003

BRASIL. Ministério da Educação. Educação Profissional Técnica de Nível Médio Integrada ao Ensino Médio. Documento Base. Brasília, 2007.

CIAVATTA, M. A formação integrada: a escola e o trabalho como lugares de memória e de identidade. In: Frigotto, G., Ciavatta, M.; Ramos, M. N. (org.). Ensino Médio Integrado: concepção e contradições. São Paulo: Cortez, 2012. p.83-106.

DAMIANI, M. F.; ROCHEFORT, Renato S.; CASTRO, Rafael Fonseca; DARIZ, Marion R.; PINHEIRO, S. N. S. Discutindo pesquisas do tipo intervenção pedagógica. Cadernos de Educação, v. 45, p.57 - 67, 2013.

FUJIMOTO, A. O. P.; MARTINS, R. A. Z. A lição de casa no processo ensino aprendizagem: um estudo de caso em Itapevi/SP. Revista Eletrônica dos discentes da Faculdade Eça de Queirós, Ano 2, n. 2, p. 1 - 72, 2013.

GRABOWSKI, G. Proposta Pedagógica: Ensino Médio Integrado à Educação Profissional. In: TV escola. Programa Salto para o futuro. Ensino Médio integrado à educação profissional. Boletim 07, 2006.

KUENZER, A. Z. As políticas de formação: a constituição da identidade do professor sobrante. Educação \& Sociedade. Ano XX, n. 68, p. 163-183, 1999.

KUENZER, A. Z. (org.). Ensino Médio: construindo uma proposta para os que vivem do trabalho. São Paulo: Cortez, 2009.

LÜDKE, M.; ANDRÉ, M. E. Pesquisa e Educação: abordagens qualitativas. São Paulo: EPU, 1986.

MACEDO, J. A.; DICKMAN, A. G.; ANDRADE, I. S. F. Simulações computacionais como ferramentas para o ensino de conceitos básicos de eletricidade. Caderno Brasileiro de Ensino de Física, v. 29, Número Especial 1, p. 562-613, 2012.

MACHADO, L. R. S. Ensino Médio e Técnico com Currículos Integrados: propostas de ação didática para uma relação não fantasiosa. In: Moll, Jaqueline. e colaboradores (org.).

Educação profissional e tecnológica no Brasil contemporâneo: desafios, tensões e possibilidades. Porto Alegre: Artmed, 2009.

MOURA, D. H. Algumas possibilidades de organização do Ensino Médio a partir de uma base unitária: trabalho, ciência, tecnologia e cultura. In: I Seminário Nacional: Currículo em Movimento - Perspectivas Atuais, I, Anais [...]. Belo Horizonte, MG, 2010. 
MOURA, D. H. A organização curricular do Ensino Médio integrado a partir do eixo estruturante: trabalho, ciência, tecnologia e cultura. Labor, n. 7, v. 1, p. 1-19, 2012.

MOURA, D. H. O Ensino Médio Integrado: perspectivas e limites na visão dos sujeitos envolvidos. In: Silva, M. da (org.). Ensino Médio Integrado: travessias. Campinas (SP): Mercado de Letras, 2013. Cap. 4, p.103-144.

NASCIMENTO, E.; AMORIM, M. Oficinas de reestruturação curricular - reflexões sobre o Ensino Médio Integrado à Educação Profissional e a ação docente. Educação \& Tecnologia, v. 13, n. 2, p. 68-71, 2008.

OLIVEIRA, J. R. S. Contribuições e abordagens experimentais no Ensino de Ciências: reunindo elementos para a prática docente. Acta Scientiae, v. 12, n. 1, p. 139-153, 2010.

RAMOS, M. N. Concepção do Ensino Médio Integrado. Natal: Secretaria de Educação do Estado do Rio Grande do Norte, 2007. p.1-30. Disponível em:

RAMOS, M. N. O currículo para o Ensino Médio em suas diferentes modalidades: concepções, propostas e problemas. Educação \& Sociedade, v. 32, n. 116, p. 771-788, 2011.

RAMOS, M. N. Possibilidades e desafios na organização do currículo integrado. In: Frigotto, G.; Ciavatta, M.; Ramos, M. N. (org.). Ensino Médio Integrado: concepção e contradições. 3. Ed. São Paulo: Cortez, 2012. p. 107 - 128.

RAMOS, M. N. Filosofia da práxis e práticas pedagógicas de Formação de trabalhadores. Trabalho \& Educação, v. 23, n. 1, p. 207-218, 2014.

SAVIANI, D. Sobre a concepção de politecnia. Rio de Janeiro: Fundação Oswaldo Cruz, 1989.

SAVIANI, D. O choque teórico da Politecnia. Trabalho, Educação e Saúde, v. 1, n. 1, p. 131-152, 2003.

SILVA, R. R.; MACHADO, P. F. L.; TUNES, E. Experimentar sem medo de errar. In: W. L. P. dos Santos; O. A. Maldaner (Orgs.). Ensino de Química em Foco. Ijuí: Unijuí, 2010. Cap. 10, p. $231-261$.

VIGOTSKI, L. S. A construção do pensamento e da linguagem. São Paulo: Martins Fontes, 2000 .

VIGOTSKI, L. S. Psicologia Pedagógica. Porto Alegre: Artmed, 2003.

Recebido em abril de 2020.

Aprovado em novembro de 2020. 